\title{
Effects of vitamin $C$ treatment on collar-induced intimal thickening
}

\author{
This article was published in the following Dove Press journal: \\ Drug Design, Development and Therapy \\ 15 December 2015 \\ Number of times this article has been viewed
}

\author{
Mehmet Zuhuri Arun' \\ Levent Üstünes' \\ Gülnur Sevin' \\ Erdener Özer² \\ 'Department of Pharmacology, Faculty \\ of Pharmacy, Ege University, Izmir, \\ Turkey; ${ }^{2}$ Department of Pathology, \\ School of Medicine, Dokuz Eylül \\ University, Izmir, Turkey
}

\begin{abstract}
Vitamin $\mathrm{C}$ has efficient antioxidant properties and is involved in important physiological processes such as collagen synthesis. As such, vitamin C deficiency leads to serious complications, including vascular diseases. The aim of this study was to investigate the effects of vitamin $\mathrm{C}$ treatment on collar-induced intimal thickening. Rabbits were fed a normocholesterolemic diet and a non-occlusive silicon collar was placed around the left carotid artery for 3, 7, and 14 days. The rabbits were treated with or without vitamin C ( $150 \mathrm{mg} / \mathrm{kg} / \mathrm{day})$. Collar-induced intimal thickening became apparent at day 7. The effect of the collar on intimal thickening was more prominent at day 14 . Vitamin $\mathrm{C}$ treatment significantly inhibited collarinduced intimal thickening at day 14. The placement of the collar around the carotid artery decreased maximum contractile responses against contractile agents $(\mathrm{KCl}$, phenylephrine, 5-hydroxytryptamine). The effect of the collar on contractile responses was enhanced as days elapsed. Decreased contractile responses of collared carotid arteries normalized at day 14 in the vitamin C treatment group. Vitamin C treatment also restored sensitivity to phenylephrine. The collar also significantly decreased acetylcholine-induced relaxations at day 3 and day 7 . Acetylcholine-induced relaxations normalized in collared-arteries in the placebo group at day 14 . Vitamin C treatment significantly increased acetylcholine-induced relaxations of both normal and collared carotid arteries at day 14. MMP-9 expression increased in collared arteries at day 3 and day 7 but did not change at day 14. MMP-2 expression increased in collared arteries at day 14 . However, vitamin $\mathrm{C}$ treatment reduced collar-stimulated expression of MMP-2 at day 14 . These findings indicate that vitamin $\mathrm{C}$ may have potentially beneficial effects on the early stages of atherosclerosis. Furthermore these results, for the first time, may indicate that vitamin $\mathrm{C}$ can also normalize decreased contractile response through perivascular collar placement.
\end{abstract}

Keywords: vitamin C, collar, intimal thickening, rabbit carotid artery, vascular reactivity, MMP

\section{Introduction}

The presence of thickened intima in atherosclerotic lesions has been recognized for nearly 150 years. ${ }^{1}$ Intimal thickening is a physiological response to vascular damage and plays a critical role in development of atherosclerosis. The vascular damage that occurs in the vessel leads to endothelial dysfunction, vascular smooth muscle cell migration, and phenotype changes. In addition, intimal thickening is a complex process and many different cell types play a role in this process at different stages. ${ }^{1}$

Considering an abundance of experimental atherosclerosis models, various cellular mechanisms of intimal thickening were studied with the aim of enlightening the process and examining different treatment approaches. Placing a non-occlusive silicone collar around the carotid artery results in expedited intimal thickening. This model has therefore been used in many studies examining intimal thickening. ${ }^{2}$ In this model, the changes at the intima layer are typically observed within 7 days and
Correspondence: Mehmet Zuhuri Arun Faculty of Pharmacy, Department of Pharmacology, Ege University, 35100, Bornova-Izmir, Turkey

Tel +902323113288

Fax +902323884687

Email mehmet.arun@ege.edu.tr 
intimal thickening reaches a maximum on the 14 th day. ${ }^{3,4}$ Feeding experimental animals a hypercholesterolemic diet allows for the examination of different early stages of atherosclerosis. ${ }^{5,6}$ Additionally, local application of various substances $^{7,8}$ and specific inhibitors or implementation of gene transfer ${ }^{9,10}$ allows researchers to study the role of different mechanisms.

It is advantageous that the changes which occur in this experimental model are limited to the region where the collar is applied and that no visible damage occurs at the endothelium layer. ${ }^{11}$ The geometric shape of applied collar is important in terms of the degree of intimal thickening., ${ }^{3,12}$ Vascular reactivity changes have also been reported in many studies that were performed using the rabbit carotid artery silicone collar model. ${ }^{13-16}$

The various experimental and clinical studies on the effects of vitamin $\mathrm{C}$ on cardiovascular diseases are worth noting. ${ }^{17}$ In many of these studies, vitamin $\mathrm{C}$ prevented endothelial dysfunction. ${ }^{18}$ Specifically, vitamin $\mathrm{C}$ is effective against oxidative stress and inflammation in the cardiovascular system. ${ }^{19}$

In light of this information, the present research aimed to study the effects of vitamin $\mathrm{C}$ on intimal thickening, vascular responses, and morphometric parameters in the rabbit carotid artery collar model which is an effective experimental model in the research of intimal thickening.

\section{Materials and methods Materials}

All agents were purchased from Sigma-Aldrich Co., St Louis, MO, USA. Primary and secondary antibodies were purchased from Thermo Fisher Scientific, Waltham, MA, USA. Vitamin $\mathrm{C}$ was kindly provided by Roche, Turkey. All agonists used in organ bath experiments were dissolved in water and diluted in a $0.9 \% \mathrm{NaCl}$ solution.

\section{Animals and treatment}

Experimental protocol was approved by the ethics committee of the University of Ege, Faculty of Pharmacy. All animals received care in compliance with the principles of laboratory animal care formulated by the National Society for Medical Research and with the Guide for the Care and Use of Laboratory Animals prepared by the Institute of Laboratory Animal Resources.

Male New Zealand White rabbits $(2-3 \mathrm{~kg})$ were housed in individual cages and had ad libitum access to laboratory chow and water throughout the experiment period. The rabbits were divided into two groups: $150 \mathrm{mg} / \mathrm{kg} /$ day vitamin $\mathrm{C}$ (freshly prepared each time) or the administration vehicle (distilled water) was administered by feeding tube ( $8 \mathrm{Ch}$, Bicakcilar, Turkey) to the rabbits.

\section{Collar-induced intimal thickening}

Placement of the collar around the carotid artery has been previously described. ${ }^{15}$ After 7 days of treatment, rabbits were anesthetized with sodium pentobarbitone, $(30 \mathrm{mg} / \mathrm{kg}$, intravenously). Both carotid arteries were surgically dissected from the surrounding tissues. A non-occlusive, flexible, biologically inert silicon collar was placed around the left carotid artery. The right carotid artery was sham-operated to expose a stretch similar to that exposed for the left carotid artery. The collar was left in position for 3 days, 7 days or 14 days. Then rabbits were killed with an overdose of sodium pentobarbitone and two segments $(3 \mathrm{~mm})$ were cut from left and right carotid arteries, one for immunohistochemistry and morphometric measurements and the other for organ bath studies. The first rings were immediately placed in a $4 \%$ buffered formalin solution for 24 hours and then embedded in paraffin blocks after routine processing.

\section{Organ bath studies}

Two rings from each carotid artery were used. Rings were mounted between two stainless steel hooks in an organ chamber filled with $25 \mathrm{~mL}$ of $37^{\circ} \mathrm{C}$ Krebs solution continuously gassed with $95 \% \mathrm{O}_{2} / 5 \% \mathrm{CO}_{2}$. The $\mathrm{Krebs}$ solution contained the following (in $\mathrm{mM}$ ): $\mathrm{NaCl}, 118 ; \mathrm{KCl}, 4.7 ; \mathrm{CaCl}_{2}, 2.5$; $\mathrm{KH}_{2} \mathrm{PO}_{4}, 1.2, \mathrm{MgSO}_{4}, 1.2 ; \mathrm{NaHCO}_{3}, 25$ and glucose, 11.1. Contractile force changes were measured with an isometric force transducer (Grass FT03; Natus Neurology Incorporated, Middleton, WI, USA) and recorded by a computer program (IOSLab 3.23, France). The carotid artery rings were gradually stretched to a tension of $6 \mathrm{~g}$. The rings were then allowed to equilibrate for 60 minutes at their optimal length. During the rest period, the Krebs solution in the organ chamber was changed every 15 minutes.

Carotid artery rings were contracted with a single dose of $\mathrm{KCl}(60 \mathrm{mM})$ at the end of the resting period. Next, concentration-response relationships to cumulative concentrations of phenylephrine $\left(10^{-9}-10^{-4} \mathrm{M}\right)$ were investigated in each ring. Cumulative concentration-relaxation curve to acetylcholine $\left(10^{-9}-10^{-4} \mathrm{M}\right)$ was constructed in the carotid artery rings followed by contraction with phenylephrine to $40 \%-60 \%$ of maximum phenylephrine contraction (submaximal contraction). Thereafter, concentration-response relationships to cumulative concentrations of serotonin $\left(10^{-9}-3 \times 10^{-5} \mathrm{M}\right)$ and nitroglycerin $\left(10^{-9}-3 \times 10^{-5} \mathrm{M}\right)$ were investigated. 


\section{Immunohistochemistry and morphometry} Immunohistochemical staining was performed for Matrix metalloproteinase (MMP)-2 and -9 (neomarkers) using avidin-biotin peroxidase method as previously described. ${ }^{20}$ Immunopositivity for MMP-2 and -9 was assessed using immunoscoring by two pathologists who were blinded to the samples. The immunoscoring procedures were performed semi-quantitatively. The staining area and staining intensity were graded on a scale from 0 to 4 . The two scores were multiplied and the immunopositivity score was determined. The scores were then used to categorize immunopositivity as weak $(\leq 2)$ or strong $(>2)$.

Transverse sections from each artery segment were cut and stained with Sirius red hematoxylin for morphometry. Images were captured at $4 \times$ magnification using Nikon Eclipse 200 (Nikon Instruments, Melville, NY, USA). The cross-sectional area of intima, media, and adventitia was traced and measured by ImageJ. The area of lumen and external elastic lamina (EEL) was calculated as previously described. ${ }^{7}$ The intima/media ratio (index) of each section was also calculated.

\section{Statistical analyses}

All data were expressed as mean \pm standard error of the mean. Relaxation responses were expressed as percentage of phenylephrine pre-contraction. The negative logarithm of molar concentration of the agonist that produced a half-maximal contraction or relaxation for that agonist $\left(\mathrm{pD}_{2}\right)$ was determined for each segment. For statistical analysis of organ bath and morphometry data, a factorial analysis of variance was used for treatment (vitamin C or placebo) between collar and sham-operated. Analysis was supplemented by an additional analysis (either a Wilcoxon signed ranked or Mann-Whitney $U$-test). A chi-square test was used to evaluate the statistical difference of immunostaining between the groups. Difference was considered significant at $P \leq 0.05$.

\section{Results Survival}

All rabbits survived and tolerated the vitamin $\mathrm{C}$ treatment without any side effects. Neither collar placement nor vitamin $\mathrm{C}$ treatment changed the weight of the rabbits.

\section{Vascular morphometry}

\section{Luminal area}

Placement of the collar around the carotid artery caused narrowing of the luminal area at day 3 and day 7. Collar-induced luminal area narrowing reached a maximum at day 14 .
Vitamin $\mathrm{C}$ treatment did not affect this narrowing of the luminal area caused by the collar (Figure 1A). Despite the fact that the data for the luminal area of carotid arteries of vitamin C-treated rabbits seemed to indicate widening of the luminal area, the widening did not reach statistical significance (Figure 1A).

\section{Tunica media}

Placement of the collar caused significant reduction on the area of tunica media at day 3 and day 7 (Figure 1B). However, this effect of the collar on the area of tunica media disappeared at day 14. Vitamin C treatment did not affect the area of tunica media in both sham-operated and collared arteries (Figure 1B).

\section{EEL}

The area of EEL for each artery was calculated. Consistent with the results of tunica media, placement of the collar around the carotid artery decreased the area of EEL as compared to the sham-operated artery (Figure 1C). Vitamin $\mathrm{C}$ treatment did not affect the area of EEL. Neither vitamin $\mathrm{C}$ treatment nor placement of the collar changed the area of EEL (Figure 1C).

\section{Tunica intima and index value}

Collar-induced intimal thickening and increased index values were first significant at day 7 (Figure 2D, E). The effects of the collar on intimal thickening and index value were more prominent at day 14 . Vitamin $\mathrm{C}$ treatment effectively reduced the intimal thickening and index value caused by the collar at day 14 (Figure 2D, E).

\section{Vascular reactivity Potassium chloride}

Contractions to a single dose of $\mathrm{KCl}$ were significantly reduced in collared rings at all days. Vitamin $\mathrm{C}$ treatment normalized these reduced contractions at day 14 in collared rings. Vitamin $\mathrm{C}$ treatment did not affect contractions to $\mathrm{KCl}$ in sham-operated rings (Figure 3A).

\section{Phenylephrine}

Placement of the collar around the carotid artery reduced contractions to phenylephrine. The inhibitory effect of the collar on phenylephrine contractions was maximized at day 14 (Figure 3B). Placement of the collar also caused decreased sensitivity to phenylephrine at all days (Table 1). Vitamin $\mathrm{C}$ treatment normalized reduced contractile response to phenylephrine at day 14 (Figure 3B). Vitamin C treatment 
A

Day 3

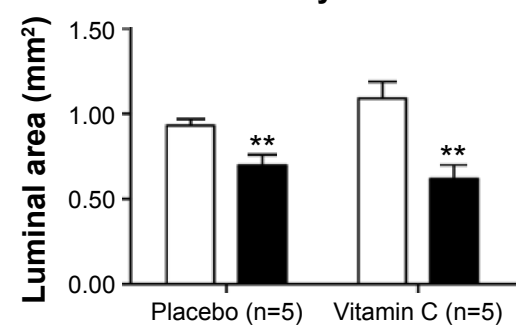

B

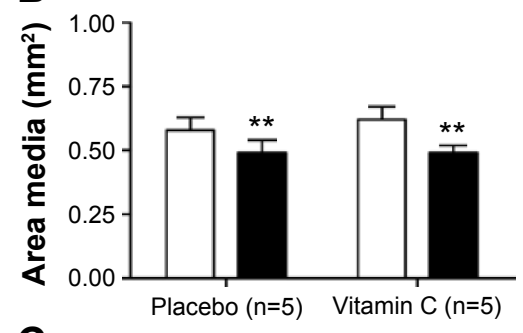

$c$

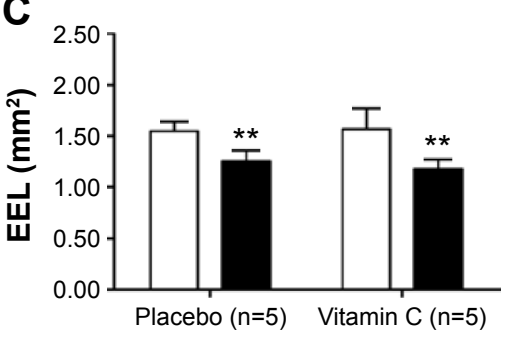

D $\square$ Sham-operated $\square$ Collared

Day 7
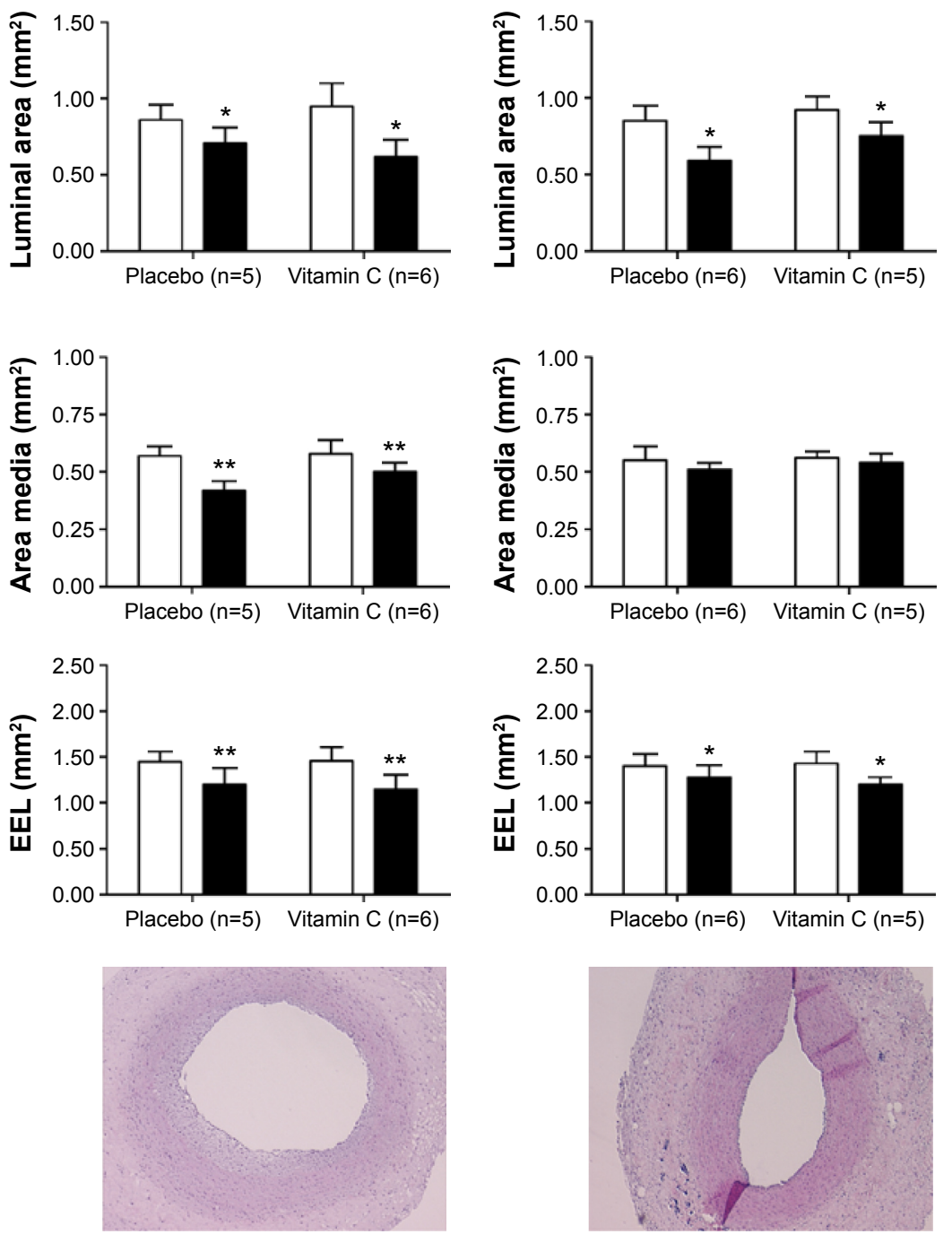

Vitamin C

Figure I Effects of collar and vitamin $C$ on vascular morphometry

Notes: Cross-sectional areas of lumen (A), media (B), and EEL (C). (D) Images of hematoxylin-eosin stained rabbit carotid arteries on day 14 . Original magnification $\times 4$. Data are expressed as mean \pm SEM. $* P \leq 0.05$, $* * P \leq 0.0$ I sham-operated vs collared; Wilcoxon signed rank test.

Abbreviations: EEL, external elastic lamina; SEM, standard error of the mean.

also normalized sensitivity to phenylephrine at day 7 and day 14 (Table 1). Vitamin C treatment did not affect contractions to phenylephrine in sham-operated rings (Figure 3B).

\section{5-hydroxytryptamine (5-HT)}

Similar to the responses to phenylephrine and $\mathrm{KCl}$, placement of the collar around the carotid artery reduced contractile responses to 5-HT (Figure 3C) at all days. On the other hand, sensitivity to 5-HT was increased by the collar (Table 1). Vitamin $\mathrm{C}$ treatment normalized decreased contractile response to 5-HT (Figure 3C) at day 14. Regardless, vitamin $\mathrm{C}$ treatment did not normalize the increased sensitivity to 5-HT (Table 1). Vitamin C treatment likewise did not affect contractions and sensitivity to 5-HT in shamoperated rings (Figure 3C).

\section{Acetylcholine}

Placement of the collar dramatically reduced the relaxation responses to acetylcholine as well as reduced sensitivity to acetylcholine on day 3 and day 7 (Figure 4A). However, placement of the collar did not affect relaxation responses to acetylcholine at day 14 . Vitamin $\mathrm{C}$ treatment did not alter the effect of the collar on acetylcholine-induced relaxations at day 3 or day 7 (Figure 4A). Interestingly, vitamin C treatment 


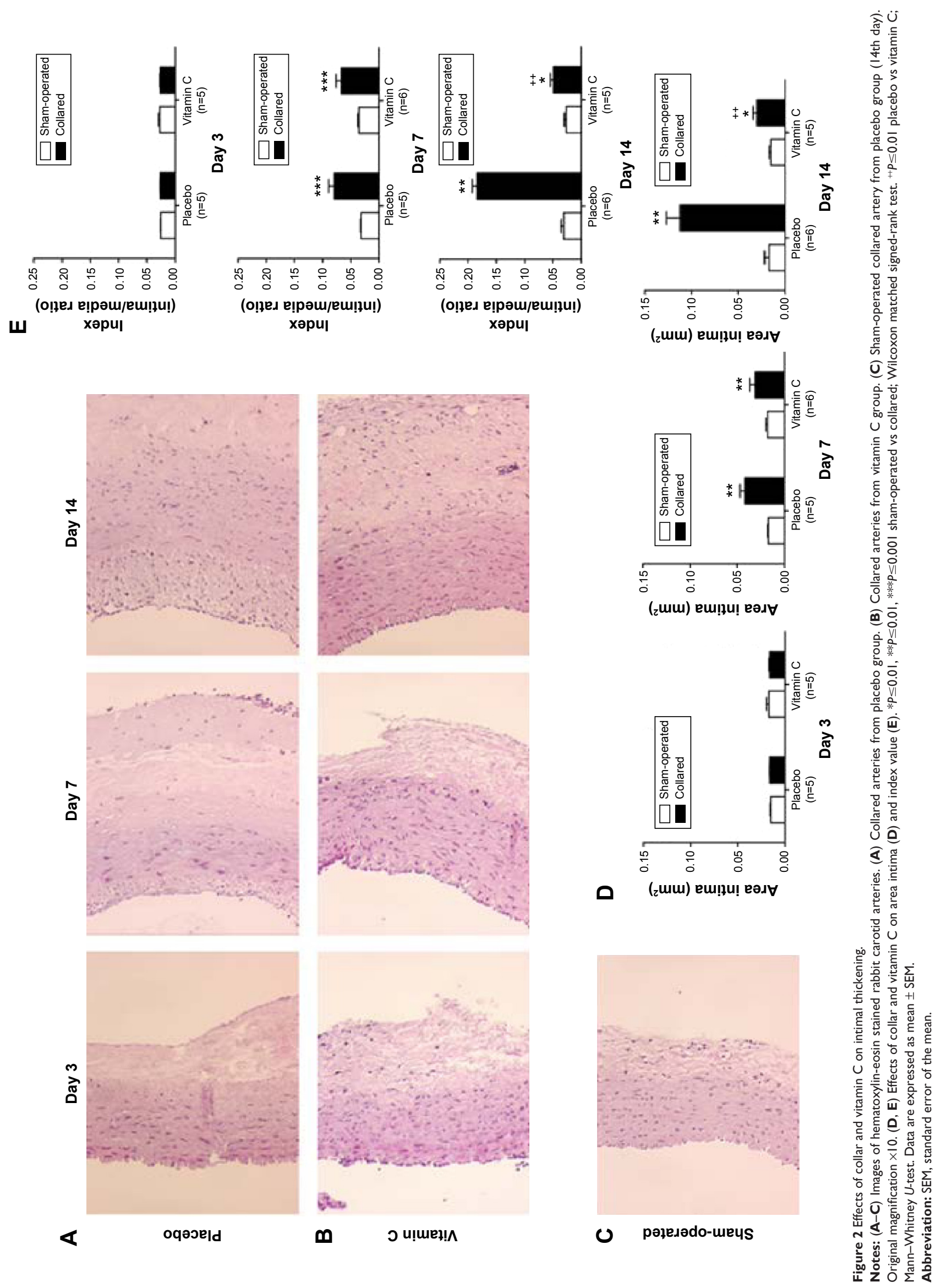


A

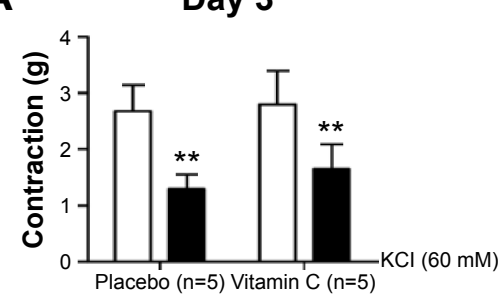

B
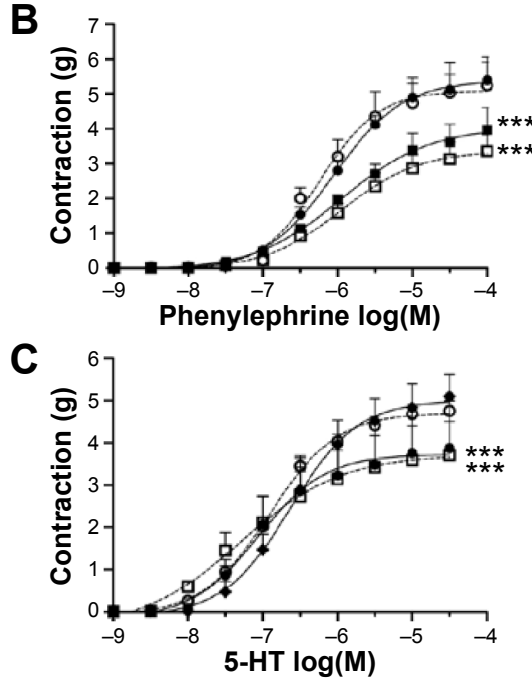

Day 7
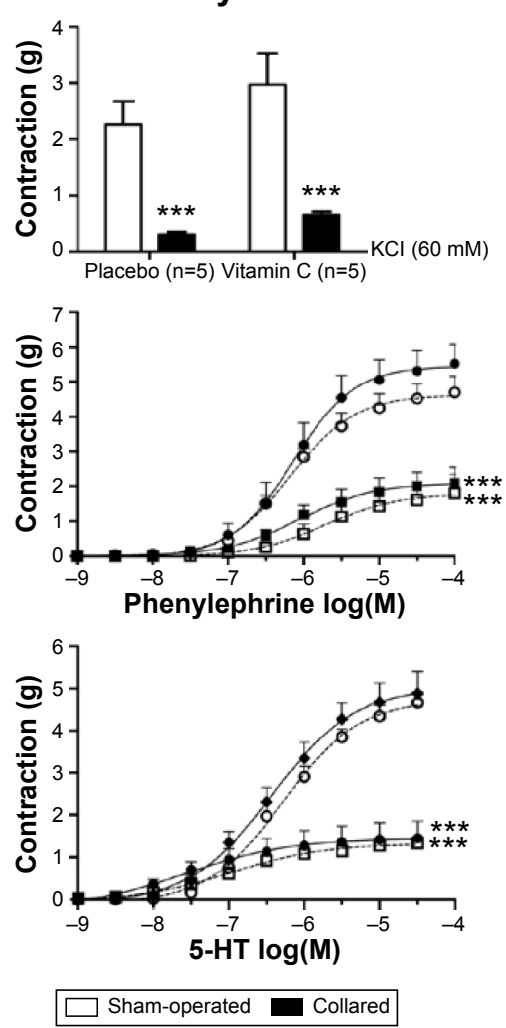

Day 14
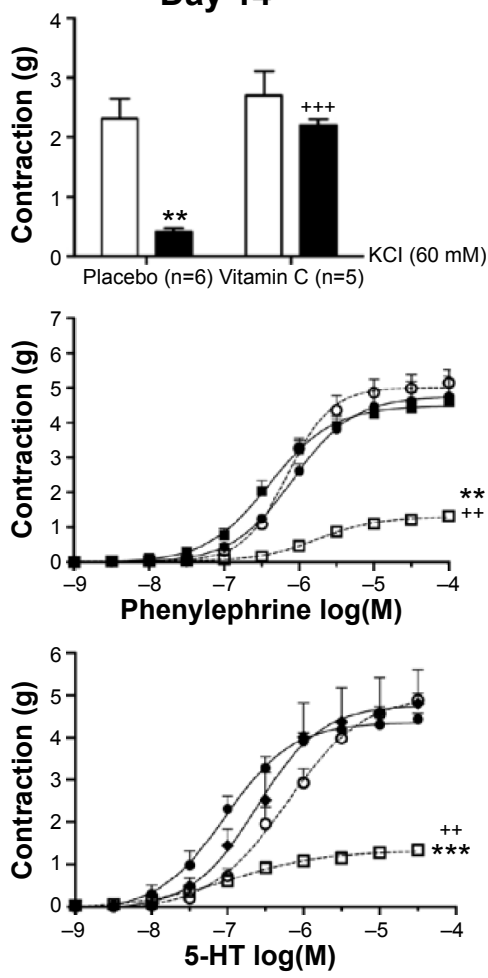

Figure 3 The effects of collar and vitamin $C$ on the vascular contractions.

Notes: The effects of collar and vitamin $\mathrm{C}$ on the vascular contractions to $\mathrm{KCl}(\mathbf{A})$, phenylephrine (B), and serotonin (C). Cumulative dose-response curves (B, C) were made both in placebo-treated sham $(O)$ and collar $(\square)$ rings and vitamin C-treated sham $(\bullet)$ and collar $(\square)$ rings. Data are expressed as mean \pm SEM. $* * P \leq 0.0$ I, ***P $\leq 0.00$ I sham-operated vs collared; Wilcoxon matched signed-rank test. ${ }^{++} P \leq 0.01,{ }^{++} P \leq 0.00$ I placebo vs vitamin C; Mann-Whitney $U$-test.

Abbreviations: SEM, standard error of the mean; 5-HT, 5-hydroxytryptamine.

Table I Effects of collar and vitamin $\mathrm{C}$ on $\mathrm{pD}_{2}$ values to phenylephrine, $5-\mathrm{HT}$ and acetylcholine

\begin{tabular}{|c|c|c|c|c|c|c|}
\hline & \multicolumn{2}{|l|}{ Phenylephrine } & \multicolumn{2}{|l|}{ 5-HT } & \multicolumn{2}{|l|}{ Acetylcholine } \\
\hline & Placebo $(n=5)$ & Vitamin $C(n=5)$ & Placebo $(n=5)$ & Vitamin $C(n=5)$ & Placebo $(n=5)$ & Vitamin $C(n=5)$ \\
\hline \multicolumn{7}{|l|}{ Day 3} \\
\hline Sham & $6.22 \pm 0.06$ & $6.13 \pm 0.07$ & $7.02 \pm 0.03$ & $6.64 \pm 0.10$ & $6.43 \pm 0.11$ & $6.85 \pm 0.13$ \\
\hline Collar & $5.93 \pm 0.04$ & $6.02 \pm 0.06$ & $7.20 \pm 0.13$ & $7.0 \mathrm{I} \pm 0.05$ & $5.66 \pm 0.10^{*}$ & $6.62 \pm 0.22^{+}$ \\
\hline \multicolumn{7}{|c|}{ Significance of factors in analysis of variance } \\
\hline - Collar & $P=0.045$ & & $P=0.031$ & & $P=0.003$ & \\
\hline - Vitamin C & NS $(P=0.64 I)$ & & $P=0.022$ & & $P=0.010$ & \\
\hline - Interaction & NS $(P=0.223)$ & & NS $(P=0.440)$ & & $P=0.040$ & \\
\hline \multicolumn{7}{|l|}{ Day 7} \\
\hline Sham & $6.15 \pm 0.11$ & $6.13 \pm 0.12$ & $6.29 \pm 0.11$ & $6.42 \pm 0.09$ & $6.74 \pm 0.03$ & $6.87 \pm 0.14$ \\
\hline Collar & $5.47 \pm 0.17^{*}$ & $6.01 \pm 0.08^{+}$ & $6.99 \pm 0.18$ & $7.33 \pm 0.10$ & $6.12 \pm 0.34$ & $5.98 \pm 0.24$ \\
\hline \multicolumn{7}{|c|}{ Significance of factors in analysis of variance } \\
\hline - Collar & $P=0.007$ & & $P=0.001$ & & $P=0.018$ & \\
\hline - Vitamin C & NS $(P=0.105)$ & & NS $(P=0.102)$ & & NS $(P=0.784)$ & \\
\hline - Interaction & $P=0.042$ & & NS $(P=0.440)$ & & NS $(P=0.490)$ & \\
\hline \multicolumn{7}{|l|}{ Day 14} \\
\hline Sham & $6.14 \pm 0.09$ & $6.11 \pm 0.08$ & $6.21 \pm 0.14$ & $6.57 \pm 0.10$ & $6.82 \pm 0.14$ & $6.74 \pm 0.09$ \\
\hline Collar & $5.78 \pm 0.07^{*}$ & $6.40 \pm 0.09^{++}$ & $6.83 \pm 0.12$ & $7.05 \pm 0.12$ & $6.52 \pm 0.18$ & $6.86 \pm 0.08$ \\
\hline \multicolumn{7}{|c|}{ Significance of factors in analysis of variance } \\
\hline - Collar & NS $(P=0.452)$ & & $P=0.001$ & & NS $(P=0.448)$ & \\
\hline - Vitamin C & $P=0.021$ & & NS $(P=0.830)$ & & NS $(P=0.147)$ & \\
\hline - Interaction & $P=0.00 \mathrm{I}$ & & NS $(P=0.5 \mid 6)$ & & NS $(P=0.991)$ & \\
\hline
\end{tabular}

Notes: Values are shown as mean \pm SEM, $\mathrm{n}$ is the number of rabbits in each group. $* P \leq 0.05$ sham-operated vs collared; Wilcoxon matched signed-rank test. ${ }^{+} P \leq 0.05$, ${ }^{++} P \leq 0.0$ I placebo vs vitamin C; Mann-Whitney U-test.

Abbreviations: 5-HT, 5-hydroxytryptamine; NS, not significant; SEM, standard error of the mean. 


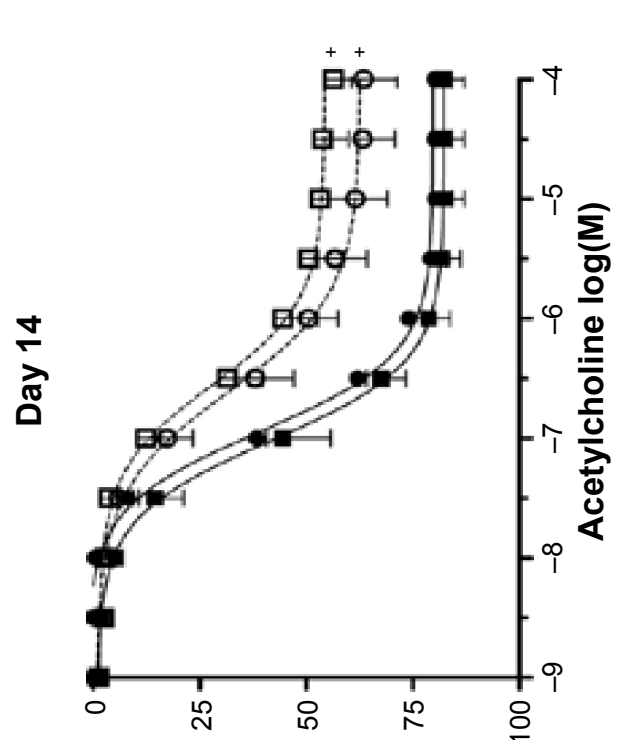

(\%) uo!jexe|әу

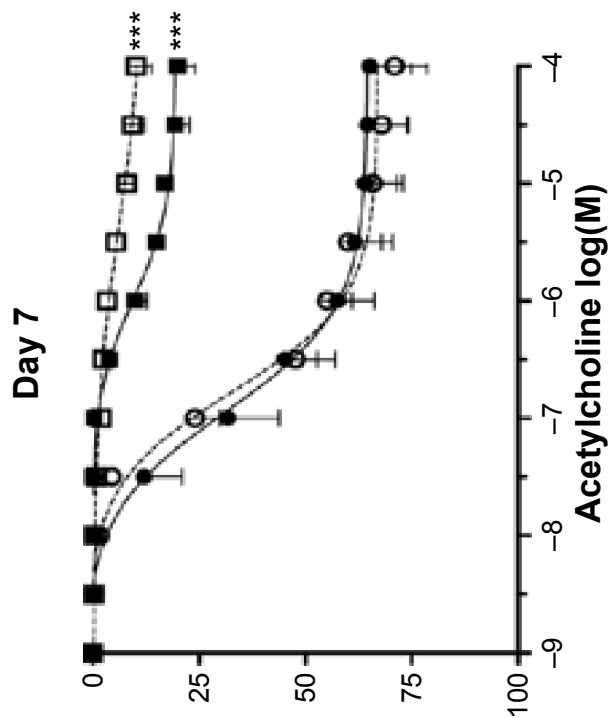

(\%) uo!jexe|әу

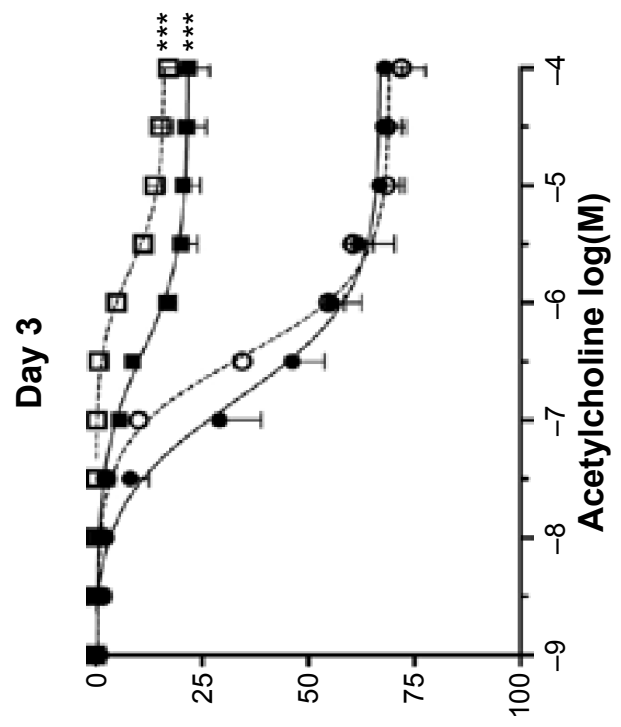

$\varangle \quad$ (\%) ио!џехерәу

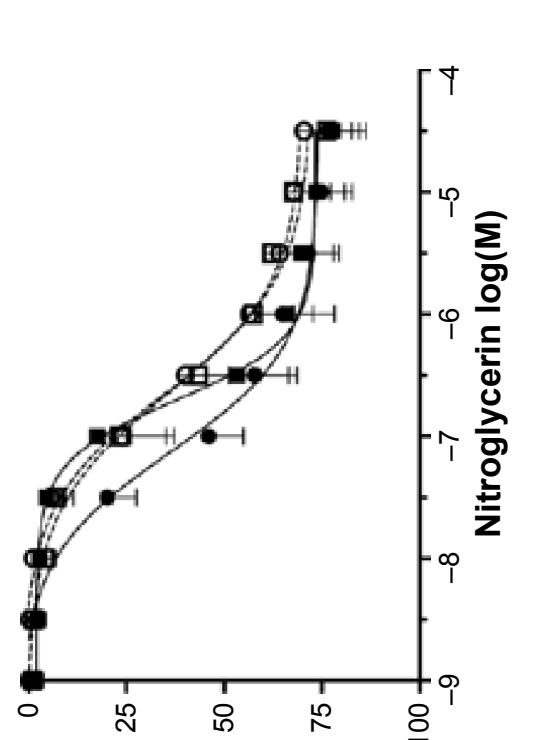

(\%) uо!łexe|әу

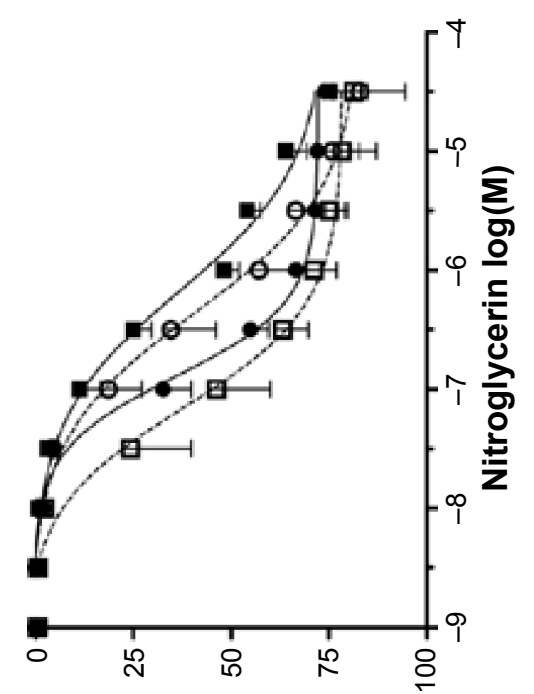

(\%) uo!̣exe|әу

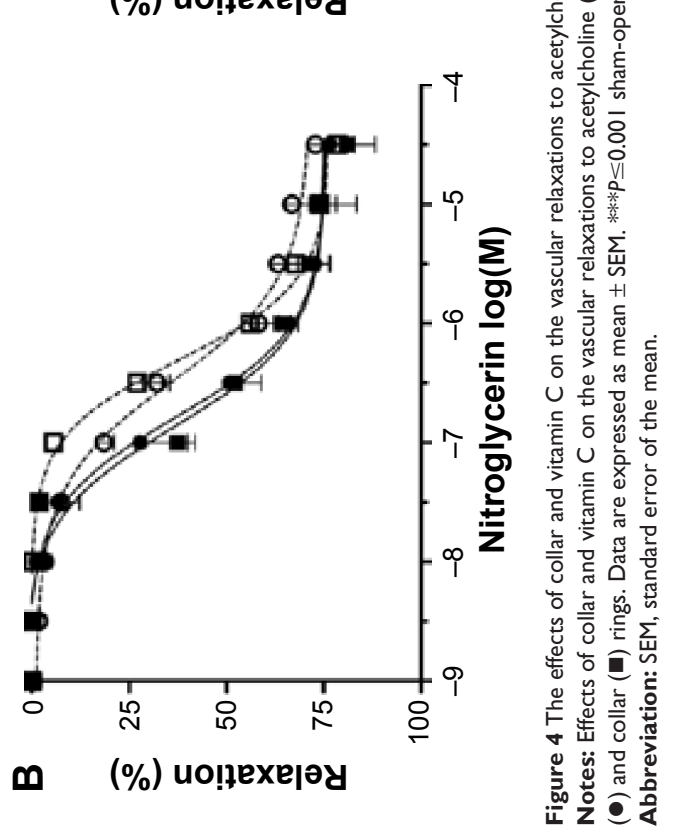



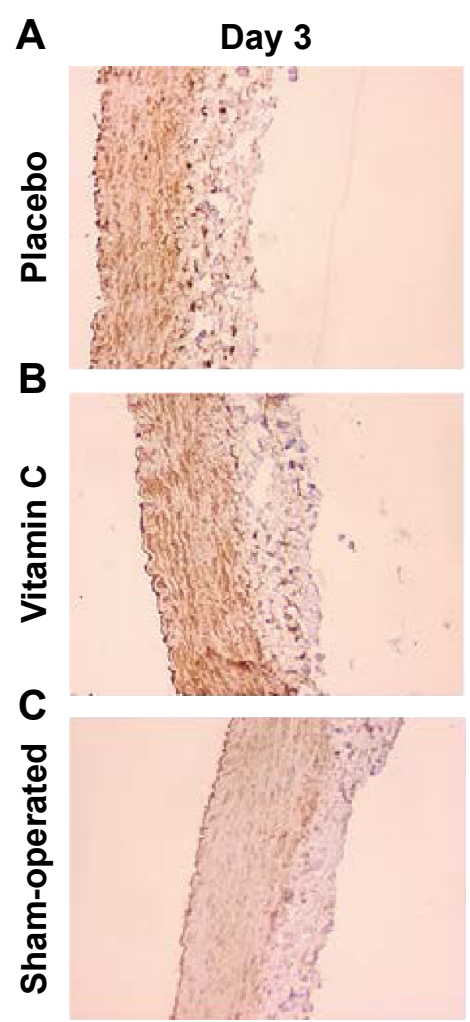

D
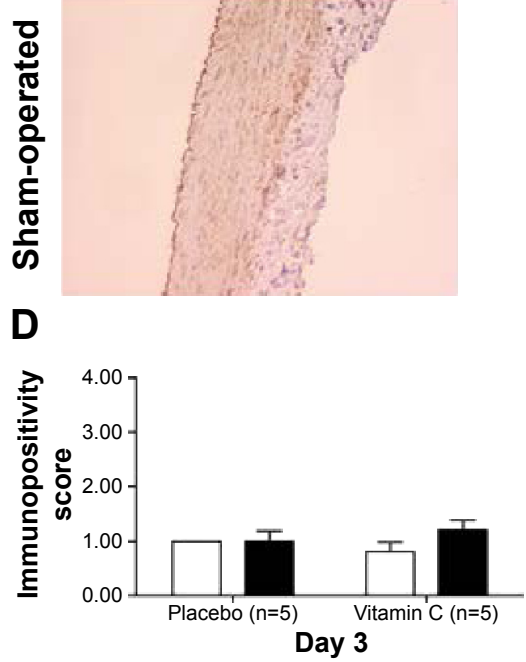

Day 7
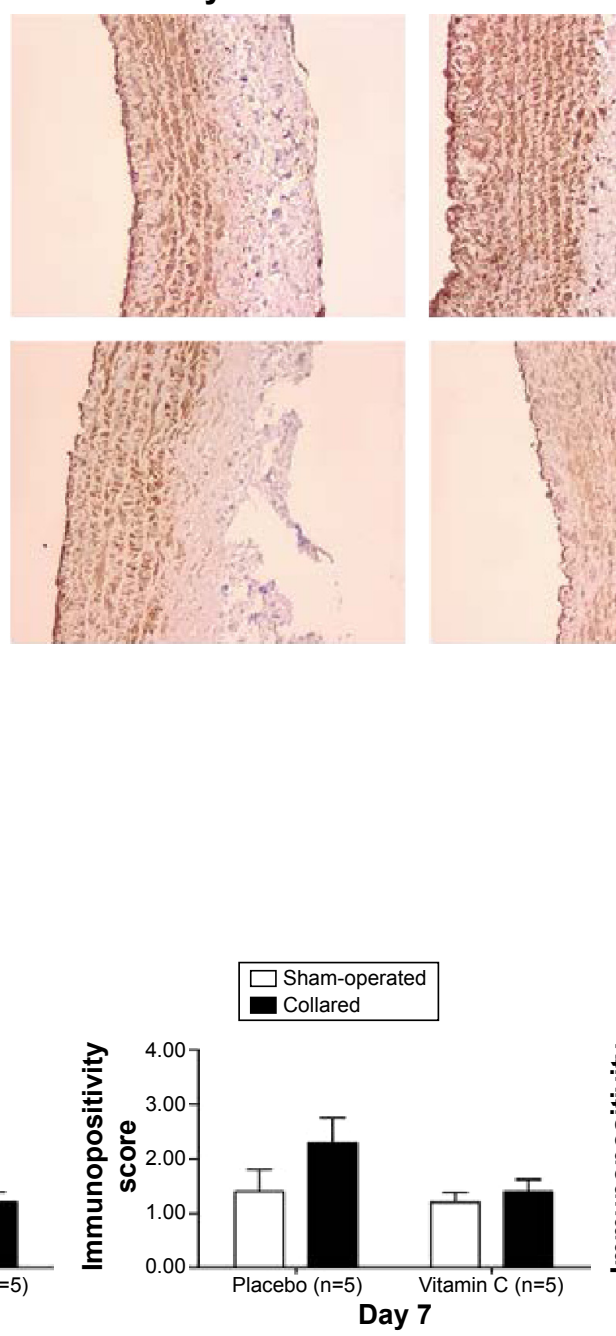

Day 14
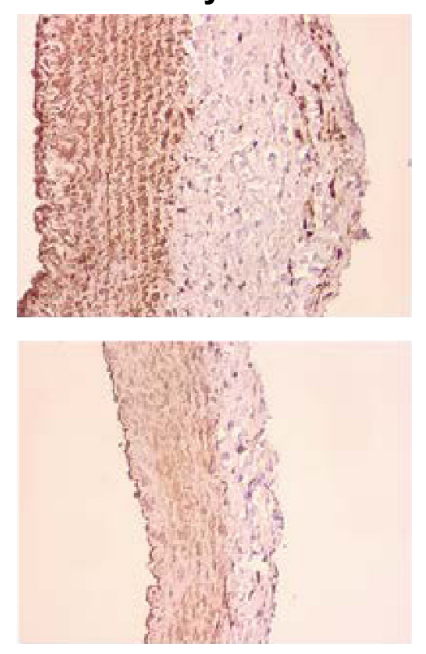

Figure 5 Effects of collar and vitamin C on MMP-2 expression.

Notes: Images of MMP-2 immunohistochemically stained rabbit carotid arteries for MMP-2. (A) Collared arteries from placebo group. (B) Collared arteries from vitamin C group. (C) Sham-operated collared artery from placebo group (I4th day). Original magnification $\times 10$. Data are expressed as mean \pm SEM. $* * P \leq 0.01$ sham-operated vs collared; chi-square test. (D) Immunopositivity scores of MMP-2 at day 3, 7 and I4.

Abbreviation: SEM, standard error of the mean.

increased acetylcholine-induced relaxations in both shamoperated and collared rings at day 14 (Figure 4A).

\section{Nitroglycerin}

Neither placement of the collar nor vitamin C treatment affected relaxation responses to nitroglycerin in phenylephrine pre-contracted rings (Figure 4B).

\section{Immunohistochemistry \\ MMP-2}

Immunoscoring data of MMP-2 showed that placement of the collar increased MMP-2 expression at day 14. Weak immunostainings of sham-operated arteries were limited at the medial area. Vitamin $\mathrm{C}$ treatment significantly inhibited increased MMP-2 expression (Figure 5).

\section{MMP-9}

Immunoscoring data of MMP-9 showed that placement of the collar significantly increased MMP-9 expression at day 3 and day 7. Immunoscoring data of MMP-9 did not show any significant difference between sham-operated and collared arteries at day 14, a finding in contrast to those previous days (Figure 6).

\section{Discussion}

In the present study, the findings demonstrated that vitamin C treatment inhibited intimal thickening caused by placement of a collar around rabbit carotid artery and normalized decreased contractile responses at day 14 . The results also showed that vitamin $\mathrm{C}$ treatment increased endothelium-dependent vasorelaxation in both collared and sham-operated arteries 
A Day 3

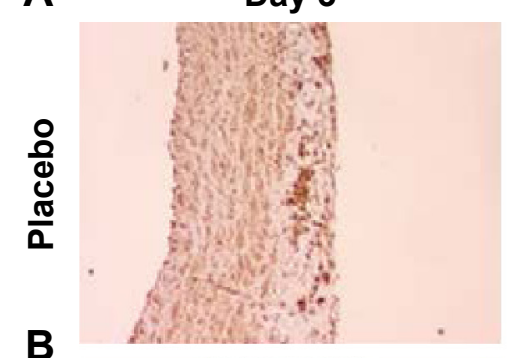

B

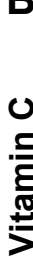

C

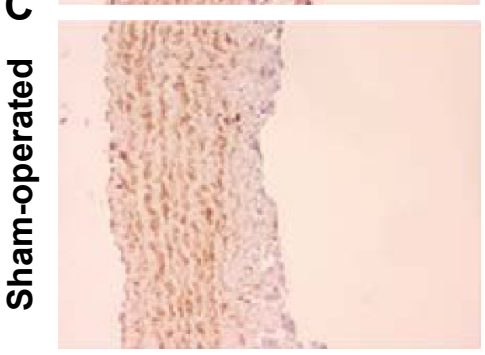

D

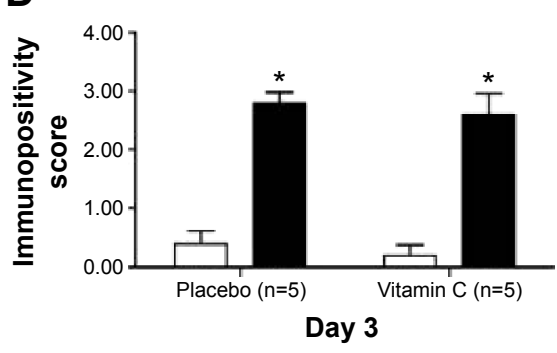

Day 7
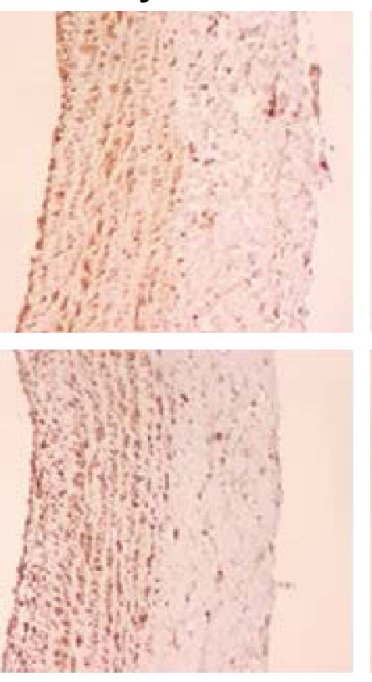

Day 14
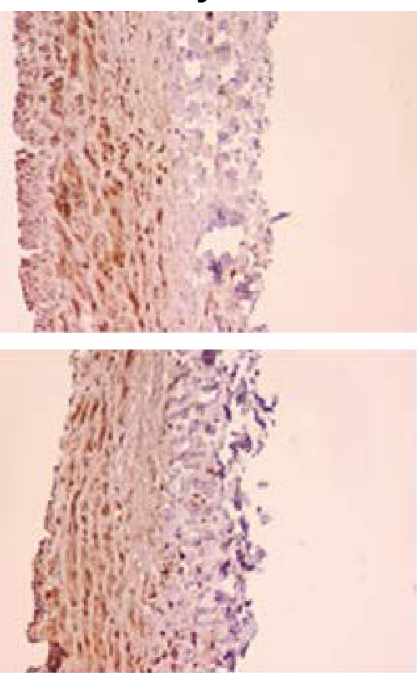
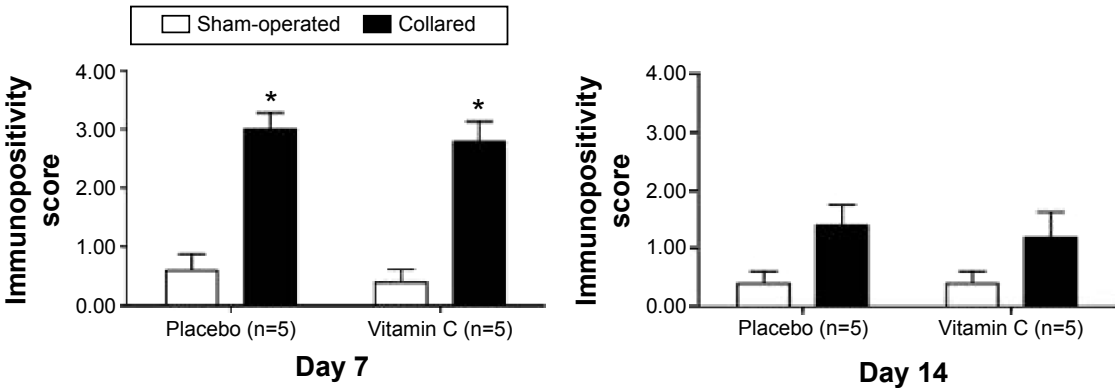

Figure 6 Effects of collar and vitamin C on MMP-9 expression.

Notes: Images of MMP-9 immunohistochemically stained rabbit carotid arteries for MMP-9. (A) Collared arteries from placebo group. (B) Collared arteries from vitamin C group. (C) Sham-operated collared artery from placebo group (I 4 th day). Original magnification $\times 10$. Data are expressed as mean \pm SEM. $* P \leq 0.05$ sham-operated vs collared; chi-square test. (D) Immunopositivity scores of MMP-9 at day 3, 7 and 14.

Abbreviation: SEM, standard error of the mean.

at day 14. Furthermore, vitamin $\mathrm{C}$ treatment also inhibited increased MMP-2 expression at day 14.

One of the most causative factors in luminal narrowing is intimal thickening. Placement of the collar caused luminal narrowing at all days in spite of there being no significant intimal thickening at day 3 . Luminal narrowing at an early stage of intimal thickening caused by the placement of a collar was previously reported. ${ }^{21}$ Yong et al reported that collaring caused decreased medial area, vasoconstriction and kinked carotid artery, in addition to changing blood flow at day 1 and day 7 of their study. ${ }^{21}$ Similarly, the results of this study showed that collar placement resulted in decreased luminal area. Additionally, a reduction in medial area occurred at day 3 and day 7 in this study. Booth et al, who defined this experimental intimal thickening model for the first time, noted in their study that collaring resulted in slight atrophy at medial layer at day $7 .^{2}$ In the current study, this finding gave rise to the concept that the combination of luminal area narrowing and decreases in EEL area with stenosis observed in the medial area at day 7 may be caused by intrinsic vascular remodeling. Vitamin $\mathrm{C}$ treatment did not demonstrate any effect on this vascular remodeling.

Intimal thickening that became apparent at day 7 and reached a maximum at day 14 was considerably inhibited by the treatment of vitamin $\mathrm{C}$ that continued for 21 days. The effect of vitamin $\mathrm{C}$ on intimal thickening did not seem robust on day 7. This may be because the dose of vitamin C was insufficient. Additionally, this phenomenon may indicate 
that different subsequent mechanisms at different stages may play a role in the development of intimal thickening.

Beneficial effects of vitamin $\mathrm{C}$ on intimal thickening have been found in many clinical and experimental studies. One study reported that a combination of vitamin $\mathrm{C}$ and vitamin $\mathrm{E}$ decreased intimal thickening in pigs in which percutaneous transluminal coronary angioplasty (PTCA) was applied. ${ }^{22}$ In a study that was performed on rats with periodontitis-induced atherosclerosis model, it was shown that vitamin $\mathrm{C}$ intake decreased the degree of atherosclerosis formed. ${ }^{23}$ In another study of older males, it was shown that there was a reverse correlation between increased vitamin $\mathrm{C}$ intake and intimal thickness as assessed over 3 years. ${ }^{24} \mathrm{~A}$ clinical study in which plasma levels of vitamin $C$ and vitamin $E$ were measured in patients with Alzheimer's disease, reported that tunica intima was thicker in the patients who had the lowest vitamin $\mathrm{C}$ plasma level. ${ }^{25}$ A combination of vitamin $\mathrm{C}$ and vitamin $\mathrm{E}$ treatment also decreased intimal index in patients who had undergone cardiac transplantation in a separate study. ${ }^{26}$

In the rabbit carotid artery collar model, it was shown that placing of the collar resulted in the formation of reactive oxygen species (ROS) and upregulated nicotinamide adenine dinucleotide phosphate (NADPH) oxidase system that was a superoxide source at all layers of carotid artery. ${ }^{27,28}$ Apocynin, an NADPH oxidase inhibitor, inhibited collar-induced intimal thickening by preventing an increase in superoxide. ${ }^{29}$ When the role of superoxide in collar-induced intimal thickening is taken into consideration, it suggests that the strong antioxidant effect of vitamin $\mathrm{C}$ may have contributed to the inhibition of intimal thickening in this study.

Vascular adhesion molecules, growth factors, and chemokines may play an important role in the intimal thickening caused by collaring., ${ }^{9,28}$ Vitamin $\mathrm{C}$ treatment may have beneficial effects on these molecules in the rabbit carotid artery collar model. Vitamin $\mathrm{C}$ can inhibit increased MCP-1 expressions. ${ }^{30,31}$ Vitamin $\mathrm{C}$ treatment may also decrease expression levels of intercellular adhesion molecule (ICAM)-1 and vascular endothelial growth factor (VEGF). ${ }^{32,33}$ Further studies that examine the relationship between these molecules and vitamin $\mathrm{C}$ will help define the underlying mechanisms of the effects of vitamin $\mathrm{C}$ on collarinduced intimal thickening.

The effects of both collaring and vitamin $\mathrm{C}$ on endothelium-dependent relaxations were examined in this study. It is known that the endothelium protects its physical integrity in the rabbit carotid artery collar model with the exception of some focal losses. ${ }^{11}$ However, it was shown in this study that there was prominent endothelial dysfunction at day 3 and day 7 following collar placement. This result is consistent with those of other studies in which acetylcholine-induced relaxations were examined. ${ }^{34,35}$ As mentioned before, oxidative stress increases relatively quickly at an early stage after placement of the collar. The relationship between increased vascular oxidative stress and decreased nitric oxide vasodilation has been shown in many clinical and experimental studies. ${ }^{36}$ This indicates that increased oxidative stress plays a significant role in collar-induced endothelial dysfunction. The absence of any difference among relaxation responses against nitroglycerine indicates that decreased acetylcholine response is not the result of a deterioration in the relaxation capacity of smooth muscle. However, these decreased acetylcholine induced relaxations were completely normalized at day 14. This finding is also consistent with other studies in which relaxation against acetylcholine was examined in a collar model. ${ }^{15,16,27,37,38}$ Intimal iNOS and eNOS activity that became apparent 5 days after placement of the collar and adventitial iNOS activity that proved its presence at the 14th day supports the existence of a natural healing process in artery wall. ${ }^{39,40}$ It was shown that vasodilation depending on endothelium was considerably maintained depending on effectivity of $\mathrm{Cu}^{+2} / \mathrm{Zn}^{+2-} \mathrm{SOD}$ despite the increase of superoxide production at the 14 th day. ${ }^{27}$

In this study, the results indicated that vitamin $\mathrm{C}$ treatment increased acetylcholine-induced relaxations in both normal and collared carotid arteries. No observed increase at day 3 and day 7 may indicate that a definite period must expire for the vitamin $\mathrm{C}$ to improve endothelium-dependent relaxations. Vitamin $\mathrm{C}$ may improve endothelial functions via various mechanisms and increase endothelium-dependent relaxations. ${ }^{18}$ In the studies performed on human endothelial cell culture and apo-E-deficient rats, vitamin $\mathrm{C}$ increased the synthesis of endothelial nitric oxide. ${ }^{41,42}$ Vitamin $C$ enhances nitric oxide synthase activity by increasing the chemical stabilization of tetrahydrobiopterin. ${ }^{41}$ Vitamin $\mathrm{C}$ treatment for 8 weeks increased acetylcholine-induced relaxations in rat thoracic aorta. ${ }^{43}$ It was reported in many clinical cases that vitamin $\mathrm{C}$ had beneficial effects on decreased endothelium-dependent relaxations in accordance with various conditions. ${ }^{44-47}$

It is known that MMPs and especially gelatinases play a critical role at the arterial wall in terms of intimal thickening. ${ }^{1}$ In a study that was performed on ovariectomized rabbits fed a cholesterol-rich diet, collaring increased MMP-2, -3, and $-9 .{ }^{5}$ In a study in which the effects of TAK044, endothelial receptor antagonist, on normocholesterolemic rabbits were examined, collaring increased MMP-2 
immunoscores and resulted in no change in immunoscores of MMP-9 at day 14. However, the researchers also reported that there was an increase in active forms of MMP-2 and -9 in collared arteries. ${ }^{20}$ Similar to previous studies, the collar led to an increase in MMP-2 immunoscores at day 14 in this study. However, it was observed for the first time in this study that there was an increase in MMP-9 immunoscores in collared arteries at day 3 and day 7 as well. Nitric oxide inhibition may lead to an increase in MMP-9 activity and expression and nitric oxide's existence may inhibit MMP-9 induction. ${ }^{48}$ The increase in MMP-9 expression observed in collared arteries, in this study occurred in parallel to endothelial dysfunction. Therefore, decreased nitric oxide amount/activity may have played a role in the MMP-9 expression. Vitamin $\mathrm{C}$ treatment demonstrated no effect on MMP-9 expression. It did, however, prominently inhibit the increase in MMP-2 expression that we observed at day 14 . Consistent with the findings from this study regarding the effects of vitamin C on MMP-2 expression, another study reported that vitamin $\mathrm{C}$ was effective in MMP-2, TIMP-1 and -2 expression in a rat abdominal aneurism model ${ }^{49}$ However, the findings from this study regarding gelatinases require further investigation, since the current study did not examine the protein expressions/mRNA levels of MMPs and activities of MMPs. Therefore, it cannot be determined whether vitamin $\mathrm{C}$ has an effect on the activities of gelatinases. Future studies that provide further insights on the expression levels, epigenetic regulation, and activities of gelatinases in different stages of collar-induced intimal thickening and how these factors interact with vitamin $\mathrm{C}$ treatment may increase the therapeutic value of vitamin $\mathrm{C}$.

In this study, collar placement dramatically decreased contractions against all contractile agents. Reduction in contraction responses after collar placement is one of the most distinguishing characteristics of the collar model. This characteristic has been demonstrated among studies in which contraction responses were examined. ${ }^{14-16,38}$ In all of these studies in which vascular reactivity was examined as well as intimal thickening, an improvement in decreased vascular contractions caused by the collar was not observed. ${ }^{15,16,38}$ As such, it was previously thought that there was no correlation between intimal thickening and decreased contraction responses. ${ }^{16}$ However, it was observed for the first time in this study that vitamin $\mathrm{C}$ nearly completely normalized decreased contraction responses as well as resulted in the inhibition of intimal thickening. These current findings draw attention to the importance of examining vascular contraction responses in intimal thickening studies. It is widely known that vascular smooth muscle cells transform into synthetic phenotypes from contractile phenotypes in damaged vessels. ${ }^{50,51}$ In their study, Reckless et al stated that there was a significant reduction in the levels of $\mathrm{CD}_{\mathrm{h}}$ isoform of caldesmon in collared arteries even at early periods when intimal thickening was hardly detected.$^{51}$ On the other hand, the levels of $\mathrm{CD}_{1}$ isoform of caldesmon increased depending on the days. ${ }^{51}$ It is remarkable that a reduction in $\mathrm{CD}_{\mathrm{b}}$ levels and an increase in $\mathrm{CD}_{1}$ levels was observed parallel to decreased contraction responses depending on the day. Within this context, normalized contractile responses in collared arteries in the vitamin $\mathrm{C}$ treatment group may be related to the effect of vitamin $\mathrm{C}$ on the expression of contractile proteins specific to vascular smooth muscle. Interestingly, a previous study demonstrated that vitamin $\mathrm{C}$ increased expressions of $h 1$-calponin, SM22 $\alpha$, and $\alpha$-actin in vascular smooth muscle cells. ${ }^{52}$ Accordingly, a subsequent in vivo study also reported that vitamin $\mathrm{C}$ stimulates expression of genes specific to smooth muscle cells in smooth muscle cells and prevents synthetic type differentiation of smooth muscle cells. ${ }^{53}$ Further investigation will broaden the researchers' knowledge of the expressions of contractile proteins and phenotypic changes of vascular smooth muscle regarding effects of vitamin $\mathrm{C}$ on intimal thickening. Additionally, increased MMP-2/-9 activity and/or expression may have a role in decreased contractions in collar-induced intimal thickening. In a study of rat aorta, MMP-2 and -9 significantly inhibited phenylephrine-induced contractions. ${ }^{54}$ Therefore, the effects of vitamin C on MMP-2 expression may contribute to its beneficial effects on decreased contractions caused by the collar.

Taken together, the findings from this study may provide new insights into the effects of vitamin $\mathrm{C}$ on intimal thickening. Furthermore, to the best of the researchers' knowledge, this study marks the first time it has been shown that vitamin $\mathrm{C}$ inhibited intimal thickening and enhanced decreased contractile responses in collar-induced intimal thickening. In terms of applicability, this study adds valuable knowledge regarding the clinical value of vitamin $\mathrm{C}$ and may serve to differentiate vitamin $\mathrm{C}$ from other antioxidants and their implications in cardiovascular disease.

\section{Acknowledgment}

This research was supported by the Scientific Research Foundation of Ege University, Izmir, Turkey.

\section{Disclosure}

The authors have no competing interests to declare. 


\section{References}

1. Newby AC. Dual role of matrix metalloproteinases (matrixins) in intimal thickening and atherosclerotic plaque rupture. Physiol Rev. 2005;85(1):1-31.

2. Booth RF, Martin JF, Honey AC, Hassall DG, Beesley JE, Moncada S. Rapid development of atherosclerotic lesions in the rabbit carotid artery induced by perivascular manipulation. Atherosclerosis. 1989; 76(2-3):257-268.

3. De Meyer GR, Van Put DJ, Kockx MM, et al. Possible mechanisms of collar-induced intimal thickening. Arterioscler Thromb Vasc Biol. 1997;17(10):1924-1930.

4. Kockx MM, De Meyer GR, Jacob WA, Bult H, Herman AG. Triphasic sequence of neointimal formation in the cuffed carotid artery of the rabbit. Arterioscler Thromb. 1992;12(12):1447-1457.

5. Bellosta S, Baetta R, Canavesi M, et al. Raloxifene inhibits matrix metalloproteinases expression and activity in macrophages and smooth muscle cells. Pharmacol Res. 2007;56(2):160-167.

6. Soma MR, Natali M, Donetti E, et al. Effect of lercanidipine and its (R)enantiomer on atherosclerotic lesions induced in hypercholesterolemic rabbits. Br J Pharmacol. 1998;125(7):1471-1476.

7. Crauwels HM, Herman AG, Bult H. Local application of advanced glycation end products and intimal hyperplasia in the rabbit collared carotid artery. Cardiovasc Res. 2000;47(1):173-182.

8. Matthys KE, Van Hove CE, Kockx MM, et al. Local application of LDL promotes intimal thickening in the collared carotid artery of the rabbit. Arterioscler Thromb Vasc Biol. 1997;17(11):2423-2429.

9. Bhardwaj S, Roy H, Heikura T, Yla-Herttuala S. VEGF-A, VEGF-D and VEGF-D(DeltaNDeltaC) induced intimal hyperplasia in carotid arteries. Eur J Clin Invest. 2005;35(11):669-676.

10. Laitinen M, Zachary I, Breier G, et al. VEGF gene transfer reduces intimal thickening via increased production of nitric oxide in carotid arteries. Hum Gene Ther. 1997;8(15):1737-1744.

11. Kockx MM, De Meyer GR, Andries LJ, Bult H, Jacob WA, Herman AG. The endothelium during cuff-induced neointima formation in the rabbit carotid artery. Arterioscle Thromb. 1993;13(12):1874-1884.

12. Kivela A, Hartikainen J, Yla-Herttuala S. Dotted collar placed around carotid artery induces asymmetric neointimal lesion formation in rabbits without intravascular manipulations. BMC Cardiovasc Disord. 2012;12:91.

13. De Meyer GR, Bult H, Martin JF, Van Hoydonck AE, Herman AG. The effect of a developing neo-intima on serotonergic and adrenergic contractions. Eur J Pharmacol. 1990;187(3):519-524.

14. De Meyer GR, Bult H, Ustunes L, et al. Vasoconstrictor responses after neo-intima formation and endothelial removal in the rabbit carotid artery. Br J Pharmacol. 1994;112(2):471-476.

15. Ustunes L, Yasa M, Kerry Z, et al. Effect of verapamil on intimal thickening and vascular reactivity in the collared carotid artery of the rabbit. Br J Pharmacol. 1996;118(7):1681-1688.

16. Van Put DJ, Van Hove CE, De Meyer GR, Wuyts F, Herman AG, Bult H. Dexamethasone influences intimal thickening and vascular reactivity in the rabbit collared carotid artery. Eur J Pharmacol. 1995; 294(2-3):753-761.

17. Oudemans-van Straaten HM, Spoelstra-de Man AM, de Waard MC. Vitamin C revisited. Crit Care. 2014;18(4):460.

18. May JM. How does ascorbic acid prevent endothelial dysfunction? Free Radic Biol Med. 2000;28(9):1421-1429.

19. Aguirre R, May JM. Inflammation in the vascular bed: importance of vitamin C. Pharmacol Ther. 2008;119(1):96-103.

20. Reel B, Oktay G, Ozkal S, et al. MMP-2 and MMP-9 alteration in response to collaring in rabbits: the effects of endothelin receptor antagonism. J Cardiovasc Pharmacol Ther. 2009;14(4):292-301.

21. Yong AC, Townley G, Boyd GW. Haemodynamic changes in the Moncada model of atherosclerosis. Clin Exp Pharmacol Physiol. 1992;19(5):339-342.

22. Nunes GL, Sgoutas DS, Redden RA, et al. Combination of vitamins $\mathrm{C}$ and $\mathrm{E}$ alters the response to coronary balloon injury in the pig. Arterioscler Thromb Vasc Biol. 1995;15(1):156-165.
23. Ekuni D, Tomofuji T, Sanbe T, et al. Vitamin C intake attenuates the degree of experimental atherosclerosis induced by periodontitis in the rat by decreasing oxidative stress. Arch Oral Biol. 2009;54(5): 495-502.

24. Ellingsen I, Seljeflot I, Arnesen H, Tonstad S. Vitamin C consumption is associated with less progression in carotid intima media thickness in elderly men: A 3-year intervention study. Nutr Metab Cardiovasc Dis. 2009;19(1):8-14.

25. Polidori MC, Ruggiero C, Croce MF, et al. Association of increased carotid intima-media thickness and lower plasma levels of vitamin C and vitamin E in old age subjects: implications for Alzheimer's disease. J Neural Transm (Vienna). 2015;122(4):523-530.

26. Ujeyl A, Fang JC, Desai AS, Mudge GH Jr, Givertz MM. Early vitamin C and $\mathrm{E}$ supplementation and cardiac allograft vasculopathy: 10-year follow-up from a randomized, controlled study. J Heart Lung Transplant. 2011;30(10):1200-1201.

27. Paravicini TM, Gulluyan LM, Dusting GJ, Drummond GR. Increased NADPH oxidase activity, gp91phox expression, and endotheliumdependent vasorelaxation during neointima formation in rabbits. Circ Res. 2002;91(1):54-61.

28. Nicholls SJ, Dusting GJ, Cutri B, et al. Reconstituted high-density lipoproteins inhibit the acute pro-oxidant and proinflammatory vascular changes induced by a periarterial collar in normocholesterolemic rabbits. Circulation. 2005;111(12):1543-1550.

29. Chan EC, Datla SR, Dilley R, Hickey H, Drummond GR, Dusting GJ. Adventitial application of the NADPH oxidase inhibitor apocynin in vivo reduces neointima formation and endothelial dysfunction in rabbits. Cardiovasc Res. 2007;75(4):710-718.

30. Loke WM, Proudfoot JM, McKinley AJ, Croft KD. Augmentation of monocyte intracellular ascorbate in vitro protects cells from oxidative damage and inflammatory responses. Biochem Biophys Res Commun. 2006;345(3):1039-1043.

31. Pan JP, Cheng TM, Chou SC, Lai ST. Vitamin C protects against lysophosphatidylcholine-induced expression of monocyte chemoattractant protein-1 in cultured human umbilical vein endothelial cells. J Formos Med Assoc. 2003;102(3):151-157.

32. Rayment SJ, Shaw J, Woollard KJ, Lunec J, Griffiths HR. Vitamin C supplementation in normal subjects reduces constitutive ICAM-1 expression. Biochem Biophys Res Commun. 2003;308(2):339-345.

33. Rodriguez JA, Nespereira B, Perez-Ilzarbe M, Eguinoa E, Paramo JA. Vitamins $C$ and E prevent endothelial VEGF and VEGFR-2 overexpression induced by porcine hypercholesterolemic LDL. Cardiovasc Res. 2005;65(3):665-673.

34. Arthur JF, Dusting GJ, Woodman OL. Impaired vasodilator function of nitric oxide associated with developing neo-intima in conscious rabbits. J Vasc Res. 1994;31(4):187-194.

35. Arthur JF, Dusting GJ. Selective endothelial dysfunction in early atheroma-like lesions in the rabbit. Coronary Artery Disease. 1992; 3(7):623-630

36. Forstermann U. Nitric oxide and oxidative stress in vascular disease. Pflugers Arch. 2010;459(6):923-939.

37. Matthys KE, Van Hove CE, Kockx MM, et al. Exposure to oxidized lowdensity lipoprotein in vivo enhances intimal thickening and selectively impairs endothelium-dependent dilation in the rabbit. Cardiovasc Res. 1998;37(1):239-246.

38. Kerry Z, Yasa M, Akpinar R, et al. Effects of nicardipine on collarinduced intimal thickening and vascular reactivity in the rabbit. J Pharm Pharmacol. 1999;51(4):441-447.

39. De Meyer GR, Kockx MM, Cromheeke KM, Seye CI, Herman AG, Bult H. Periadventitial inducible nitric oxide synthase expression and intimal thickening. Arterioscler Thromb Vasc Biol. 2000;20(8):1896-1902.

40. Arthur JF, Yin ZL, Young HM, Dusting GJ. Induction of nitric oxide synthase in the neointima induced by a periarterial collar in rabbits. Arterioscler Thromb Vasc Biol. 1997;17(4):737-740.

41. Heller R, Unbehaun A, Schellenberg B, Mayer B, Werner-Felmayer G, Werner ER. L-ascorbic acid potentiates endothelial nitric oxide synthesis via a chemical stabilization of tetrahydrobiopterin. J Biol Chem. $2001 ; 276(1): 40-47$. 
42. d'Uscio LV, Milstien S, Richardson D, Smith L, Katusic ZS. Long-term vitamin $\mathrm{C}$ treatment increases vascular tetrahydrobiopterin levels and nitric oxide synthase activity. Circ Res. 2002;92(1):88-95.

43. Ettarh RR, Sofola OA, Adigun SA. Role of the endothelium in the vascular effects of vitamin C in rats. Pathophysiology. 2003;9(2):97-101.

44. Motoyama T, Kawano H, Kugiyama K, et al. Endothelium-dependent vasodilation in the brachial artery is impaired in smokers: effect of vitamin C. Am J Physiol. 1997;273(4 Pt 2):H1644-H1650.

45. Ting HH, Timimi FK, Haley EA, Roddy MA, Ganz P, Creager MA. Vitamin $\mathrm{C}$ improves endothelium-dependent vasodilation in forearm resistance vessels of humans with hypercholesterolemia. Circulation. 1997;95(12):2617-2622.

46. Timimi FK, Ting HH, Haley EA, Roddy MA, Ganz P, Creager MA. Vitamin $\mathrm{C}$ improves endothelium-dependent vasodilation in patients with insulin-dependent diabetes mellitus. J Am Coll Cardiol. 1998; 31(3):552-557.

47. McSorley PT, Young IS, Bell PM, Fee JP, McCance DR. Vitamin C improves endothelial function in healthy estrogen-deficient postmenopausal women. Climacteric. 2003;6(3):238-247.

48. O’Sullivan S, Medina C, Ledwidge M, Radomski MW, Gilmer JF. Nitric oxide-matrix metaloproteinase-9 interactions: biological and pharmacological significance - NO and MMP-9 interactions. Biochim Biophys Acta. 2014;1843(3):603-617.
49. Tanaka A, Hasegawa T, Morimoto K, et al. Controlled release of ascorbic acid from gelatin hydrogel attenuates abdominal aortic aneurysm formation in rat experimental abdominal aortic aneurysm model. J Vasc Surg. 2014;60(3):749-758.

50. Kocher O, Gabbiani F, Gabbiani G, et al. Phenotypic features of smooth muscle cells during the evolution of experimental carotid artery intimal thickening. Biochemical and morphologic studies. Lab Invest. 1991;65(4):459-470.

51. Reckless J, Fleetwood G, Tilling L, Huber PA, Marston SB, Pritchard K. Changes in the caldesmon isoform content and intimal thickening in the rabbit carotid artery induced by a silicone elastomer collar. Arterioscler Thromb. 1994;14(11):1837-1845.

52. Arakawa E, Hasegawa K, Yanai N, Obinata M, Matsuda Y. A mouse bone marrow stromal cell line, TBR-B, shows inducible expression of smooth muscle-specific genes. FEBS Lett. 2000;481(2):193-196.

53. Arakawa E, Hasegawa K, Irie J, et al. L-ascorbic acid stimulates expression of smooth muscle-specific markers in smooth muscle cells both in vitro and in vivo. J Cardiovasc Pharmacol. 2003;42(6):745-751.

54. Chew DK, Conte MS, Khalil RA. Matrix metalloproteinase-specific inhibition of $\mathrm{Ca} 2+$ entry mechanisms of vascular contraction. $J$ Vasc Surg. 2004;40(5):1001-1010.

\section{Publish your work in this journal}

Drug Design, Development and Therapy is an international, peerreviewed open-access journal that spans the spectrum of drug design and development through to clinical applications. Clinical outcomes, patient safety, and programs for the development and effective, safe, and sustained use of medicines are a feature of the journal, which

\section{Dovepress}

has also been accepted for indexing on PubMed Central. The manuscript management system is completely online and includes a very quick and fair peer-review system, which is all easy to use. Visit http://www.dovepress.com/testimonials.php to read real quotes from published authors.

Submit your manuscript here: http://www.dovepress.com/drug-design-development-and-therapy-journal 